\title{
CONJUGATE MIXED CONVECTION IN AIR-COOLED HEAT SINKS USING A NON-BOUSSINESQ APPROACH
}

\author{
C. R. de Andrade, \\ A. V. Pantaleão and \\ E. L. Zaparoli \\ ABSTRACT \\ This work reports a numerical study of the mixed convection in finned duct flow that \\ occurs in heat sinks devices. The laminar flow is considered fully developed and the \\ convection-conduction coupling is treated by a conjugated approach. The mathematical \\ formulation of this problem is constituted by the mass, momentum and energy equations. \\ The partial differential equations system is solved by the Galerkin finite element method, \\ adopting a pressure Poisson equation to establish the pressure-velocity coupling and to \\ obtain a mass conserving flow. The results using the classical Boussinesq approximation \\ (density varies linearly with the temperature in the buoyancy-term) are compared with \\ the non-Boussinesq approach (density variation in all terms of the governing equations) \\ showing that both the heat transfer and friction factor are affected by the new \\ considerations. The duct aspect ratio and the solid to fluid thermal conductivity ratio \\ influences on the heat transfer rate are also analyzed. This analysis tool was also shown \\ appropriate for the optimization of electronic components air-cooled heat sinks.
}

\section{INTRODUCTION}

The plate-fin heat sink has been frequently used to provide thermal control for electronic components. They are applied in the cooling of microprocessors, power transistors, and other electronic modules. Most air-cooled heat sinks are manufactured by stamping or extrusion processes and some available commercial heat sinks are shown in Lorenzetti (1989). The passive heat sinks are cooled by air natural convection while in the active dissipators the heat is transferred to a fan induced air coolant flow. So, the heat dissipation can be enhanced by the combined effect of free and forced convection in the equipment (named mixed convection). In this process, the main axial flow is superimposed by a secondary flow at the transversal section of the plate-fin due to the buoyancy force.

Generally, the laminar mixed convection problem is analyzed upon the Boussinesq approximation. This approach involves two aspects: first, the density variation in the continuity equation is neglected resulting in a zero divergence of the velocity vector; second, density variation from a mean value is supposed linearly dependent from the temperature only in the buoyancy force term of the momentum equation. This approach has been employed to study the natural and mixed convection in different geometries.

Sillekens et al. (1998) investigated the laminar mixed convection flow in a horizontal channel heated from the side walls. The governing equations system is simplified using the Boussinesq approximation and is solved by a finite element method. Their numerical code is validated by a comparison with particle tracking experimental results for the velocity fields.

Krauss and Bar-Cohen (1995) presented an extensive study of both natural and forced convection flow through parallel-plate channels, fins conduction and radiative heat transfer applied to the design and optimization of these heat sinks. According to these authors, the determination of the heat sink performance should consider a conjugate solution of the convectionconduction problem. In the conjugated approach the solid and the fluid regions are studied as an unique domain (Davis and Gill, 1970). The equilibrium conditions (temperature and heat flux) at the solid-fluid interface are implicitly imposed by the solution method.

DeAndrade and Zaparoli (2000) reported a numerical study of the conjugated mixed convection in finned duct flow. They employed the Boussinesq approach adopting a pressure Poisson equation to establish the pressure-velocity coupling. The effect of duct aspect ratio on the heat transfer rate and friction coefficient is analyzed and the data are compared with parallel-plate case. Also the influence of the fluid to wall conductivity ratio in the Nusselt number results was studied.

Morcos and Bergles (1975) obtained experimental results for the effects of property variations on fully developed laminar mixed convection in horizontal tubes. They showed that the heat transfer and friction factor data were above the constant properties predictions.

Zhong et al (1985) studied numerically the influence of variable properties on the temperature and velocity fields and the heat transfer rate in a differentially heated two-dimensional square cavity employing the Boussinesq approach. Their work is aimed to analyze the validity of the Boussinesq approximation for that geometric configuration.

At this context, the present work deals with the conjugate mixed convection in air-cooled heat sinks using a non-Boussinesq approach. The density variation is taken account in all terms of the governing equations (continuity, energy and momentum). The heat transfer results are compared with the classical Boussinesq approach ones (where the density variation is considered only in the buoyancy-term of the y-momentum equation) and show that the Nusselt number values increases when 


\section{CIÊNCIA/SCIENCE}

the non-Boussinesq is employed for the Rayleigh number range studied.

\section{MATHEMATICAL FORMULATION}

At this work, a steady-state laminar mixed convection problem is numerically simulated. The heat removing system is composed by a finned base plate and a isolated flat cover with a coolant air-flow passing trough the duct, as shown in Fig. 1. By employing the symmetry plains, the computational domain can be simplified as shown in Fig. 2.

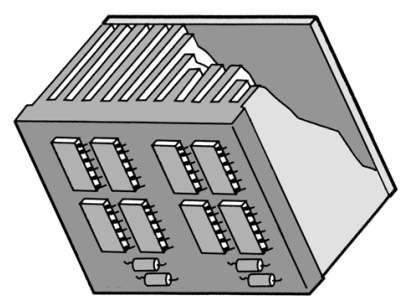

Figure 1. Air-cooled heat sink equipment

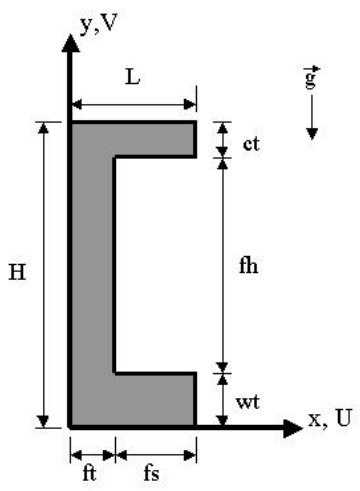

Figure 2. Computational domain: $\mathrm{fh}$ - fin height; $\mathrm{ft}-$ fin thickness; wt - wall thickness; fs - fin spacing; ct cover thickness.

The thermal and hydrodynamic fully developed conditions are expressed by:

$\frac{\partial \mathrm{T}}{\partial \mathrm{Z}}=\frac{\partial \mathrm{T}_{\mathrm{w}}}{\partial \mathrm{Z}}=\frac{\mathrm{dT}_{\mathrm{b}}}{\mathrm{dZ}}$

and

$\frac{\partial(\rho U)}{\partial X}=\frac{\partial(\rho \mathrm{V})}{\partial \mathrm{Y}}=\frac{\partial(\rho \mathrm{W})}{\partial \mathrm{Z}}=0$

with:

$\rho \quad=$ fluid density

$\mathrm{Z} \quad=$ axial coordinate

$\mathrm{X}=$ horizontal coordinate in the duct cross-section

$\mathrm{Y} \quad=$ vertical coordinate in the duct cross-section

$\mathrm{W} \quad=$ velocity component in the Z-direction; (main

flow);

$\mathrm{U}$ and $\mathrm{V}=$ velocity components in the cross-section (secondary flow);

$\mathrm{T}=$ temperature field

$\mathrm{T}_{\mathrm{w}} \quad=$ wall temperature at $\mathrm{Y}=0$ and $0 \leq \mathrm{X} \leq(\mathrm{ft}+\mathrm{fs})$

$\mathrm{T}_{\mathrm{b}} \quad=$ fluid bulk temperature calculated as:
C. R. de Andrade et al. Conjugate Mixed Convection...

$$
\mathrm{T}_{\mathrm{b}}=\frac{\int(\rho \mathrm{CpWT}) \mathrm{dXdY}}{\int(\rho \mathrm{CpW}) \mathrm{dXdY}}
$$

where $\mathrm{Cp}$ is the fluid constant pressure specific heat.

The density varies inversely as a function of the temperature in all terms of the governing equations as follow:

$\rho=\frac{\rho_{\mathrm{w}} \mathrm{T}_{\mathrm{w}}}{\mathrm{T}}$

where $\rho_{\mathrm{w}}$ is the density at wall temperature.

The governing system equations are formulated as follows:

․ Continuity equation:

$$
\begin{aligned}
& \frac{\partial(\rho \mathrm{U})}{\partial \mathrm{X}}+\frac{\partial(\rho \mathrm{V})}{\partial \mathrm{Y}}=0 \\
& \quad \quad \text { Momentum equation in } \mathrm{X} \text {-axis: } \\
& \rho\left(\mathrm{U} \frac{\partial \mathrm{U}}{\partial \mathrm{X}}+\mathrm{V} \frac{\partial \mathrm{U}}{\partial \mathrm{Y}}\right)=-\frac{\partial \mathrm{P}}{\partial \mathrm{X}}+\bar{\mu} \nabla^{2} \mathrm{U}+\phi_{\mathrm{X}}
\end{aligned}
$$

with

$$
\begin{gathered}
\phi_{\mathrm{x}}=-\frac{\rho \mathrm{UW}}{\mathrm{T}} \frac{\mathrm{dT}_{\mathrm{b}}}{\mathrm{dZ}}+\frac{\bar{\mu}}{3} \frac{\partial}{\partial \mathrm{X}}\left(\frac{\partial \mathrm{U}}{\partial \mathrm{X}}+\frac{\partial \mathrm{V}}{\partial \mathrm{Y}}+\frac{\mathrm{W}}{\mathrm{T}} \frac{\mathrm{dT}_{\mathrm{b}}}{\mathrm{dZ}}\right) \\
\square \quad \text { Momentum equation in } \mathrm{Y} \text {-axis: } \\
\rho\left(\mathrm{U} \frac{\partial \mathrm{V}}{\partial \mathrm{X}}+\mathrm{V} \frac{\partial \mathrm{V}}{\partial \mathrm{Y}}\right)=\rho g_{\mathrm{y}}-\frac{\partial \mathrm{P}}{\partial \mathrm{Y}}+\bar{\mu} \nabla^{2} \mathrm{~V}+\phi_{\mathrm{y}}
\end{gathered}
$$

with

$$
\phi_{\mathrm{y}}=-\frac{\rho \mathrm{VW}}{\mathrm{T}} \frac{\mathrm{dT}_{\mathrm{b}}}{\mathrm{dZ}}+\frac{\bar{\mu}}{3} \frac{\partial}{\partial \mathrm{Y}}\left(\frac{\partial \mathrm{U}}{\partial \mathrm{X}}+\frac{\partial \mathrm{V}}{\partial \mathrm{Y}}+\frac{\mathrm{W}}{\mathrm{T}} \frac{\mathrm{dT}_{\mathrm{b}}}{\mathrm{dZ}}\right)
$$

a Momentum equation in Z-axis:

$$
\rho\left(\mathrm{U} \frac{\partial \mathrm{W}}{\partial \mathrm{X}}+\mathrm{V} \frac{\partial \mathrm{W}}{\partial \mathrm{Y}}\right)=-\frac{\partial \mathrm{P}^{\prime}}{\partial \mathrm{Z}}+\bar{\mu} \nabla^{2} \mathrm{~W}+\phi_{\mathrm{Z}}
$$

with

$$
\phi_{\mathrm{Z}}=-\frac{\rho \mathrm{WW}}{\mathrm{T}} \frac{\mathrm{dT}_{\mathrm{b}}}{\mathrm{dZ}}+\bar{\mu} \frac{\partial}{\partial \mathrm{X}}\left(\frac{\mathrm{U}}{\mathrm{T}} \frac{\mathrm{dT}_{\mathrm{b}}}{\mathrm{dZ}}\right)+\bar{\mu} \frac{\partial}{\partial \mathrm{Y}}\left(\frac{\mathrm{V}}{\mathrm{T}} \frac{\mathrm{dT}_{\mathrm{b}}}{\mathrm{dZ}}\right)
$$

\section{ㅁ Energy equation:}

$$
\begin{aligned}
& \overline{\mathrm{k}} \nabla^{2} \mathrm{~T}=\rho \mathrm{Cp}\left(\mathrm{U} \frac{\partial \mathrm{T}}{\partial \mathrm{X}}+\mathrm{V} \frac{\partial \mathrm{T}}{\partial \mathrm{Y}}+\mathrm{W} \frac{\mathrm{dT}_{\mathrm{b}}}{\mathrm{dz}}\right) \\
& \text { where: } \nabla^{2}\left(\mathrm{)}=\frac{\partial^{2}()}{\partial \mathrm{X}^{2}}+\frac{\partial^{2}()}{\partial \mathrm{Y}^{2}} ; \mathrm{g}_{\mathrm{y}}=\right.\text { gravity }
\end{aligned}
$$

acceleration vector; $\mathrm{k}=$ thermal conductivity; $\mu=$ dynamic viscosity; $\overline{\mathrm{k}}=\frac{\mathrm{k}_{\mathrm{s}}}{\mathrm{k}_{\mathrm{f}}} ;$ and $\bar{\mu}=\frac{\mu_{\mathrm{s}}}{\mu_{\mathrm{f}}} \quad$.The subscripts "s" and "f " refer to the solid and fluid domains, respectively.

In this work the motion pressure $\mathrm{P}^{*}(\mathrm{x}, \mathrm{y}, \mathrm{z})$ is separated in a axial contribution and in a parcel corresponding to the transversal direction as mentioned in Fletcher (1991) described as:

$$
\mathrm{P}^{*}(\mathrm{x}, \mathrm{y}, \mathrm{z})=\mathrm{P}^{\prime}(\mathrm{z})+\mathrm{P}(\mathrm{x}, \mathrm{y})
$$




\section{CIÊNCIA/SCIENCE}

where $\mathrm{P}^{*}(\mathrm{x}, \mathrm{y}, \mathrm{z})$ is defined as the difference between the static pressure, $\mathrm{P}^{+}(\mathrm{x}, \mathrm{y}, \mathrm{z})$, and the hydrostatic pressure:

$$
\vec{\nabla} \mathrm{P}^{*}(\mathrm{x}, \mathrm{y}, \mathrm{z})=\vec{\nabla} \mathrm{P}^{+}(\mathrm{x}, \mathrm{y}, \mathrm{z})-\rho_{\mathrm{w}} \overrightarrow{\mathrm{g}}
$$

The boundary conditions for the problem are (see Fig. 2)

$$
\begin{aligned}
& \text { At } \mathrm{X}=0,0 \leq \mathrm{Y} \leq \mathrm{H} / \mathrm{fh}: \\
& \mathrm{U}=\mathrm{V}=\mathrm{W}=0 ; \partial \mathrm{T} / \partial \mathrm{X}=0 \\
& \text { At } \mathrm{Y}=0,0 \leq \mathrm{X} \leq \mathrm{L} / \mathrm{fh}: \\
& \mathrm{U}=\mathrm{V}=\mathrm{W}=0 ; \mathrm{T}=\mathrm{T}_{\mathrm{w}} \\
& \text { At } \mathrm{X}=\mathrm{L} / \mathrm{fh}, 0 \leq \mathrm{Y} \leq \mathrm{H} / \mathrm{fh}: \\
& \mathrm{U}=0, \partial \mathrm{V} / \partial \mathrm{X}=\partial \mathrm{W} / \partial \mathrm{X}=\partial \mathrm{T} / \partial \mathrm{X}=0 \\
& \text { At } \mathrm{Y}=\mathrm{H} / \mathrm{fh}, 0 \leq \mathrm{X} \leq \mathrm{L} / \mathrm{fh}: \\
& \mathrm{U}=\mathrm{V}=\mathrm{W}=0 ; \partial \mathrm{T} / \partial \mathrm{Y}=0
\end{aligned}
$$

Combining Eqs. (4), (5) and (6) a pressure Poisson equation was obtained to establish the pressurevelocity coupling and to impose a mass conserving flow.

The convection coefficient (h) is defined as:

$h=\frac{q_{w m}}{\left(T_{w}-T_{b}\right)}$,

where

$\mathrm{q}_{\mathrm{wm}}=\left(\frac{1}{\mathrm{fs}+\mathrm{ft}}\right) \int_{0}^{(\mathrm{fs}+\mathrm{ft})}\left(-\left.\mathrm{k}_{\mathrm{s}} \frac{\partial \mathrm{T}}{\partial \mathrm{Y}}\right|_{\mathrm{Y}=0}\right) \mathrm{dX}$

and the Nusselt number is expressed by:

$$
\mathrm{Nu}=\frac{\mathrm{h}(2 \mathrm{fh})}{\mathrm{k}_{\mathrm{f}}}
$$

A fluid mean-velocity is calculated as:

$$
\mathrm{W}_{\mathrm{m}}=\frac{1}{(\mathrm{fs} \cdot \mathrm{fh})} \int \mathrm{W} \mathrm{dXdY}
$$

and the friction factor is given by:

$$
f=\frac{-4 \mathrm{fh}(\mathrm{dP} / \mathrm{dZ})}{\rho_{\mathrm{W}}\left(\mathrm{W}_{\mathrm{m}}\right)^{2}}
$$

where $\mathrm{dP} / \mathrm{dZ}$ is the axial main flow pressure gradient.

The Reynolds and Rayleigh numbers are given by:

$$
\begin{aligned}
& \operatorname{Re}=\frac{\rho_{\mathrm{w}} \mathrm{W}_{\mathrm{m}}(2 \mathrm{fh})}{\mu_{\mathrm{f}}} \text { and } \\
& \quad \mathrm{Ra}=\frac{\mathrm{g}_{\mathrm{y}} \beta\left(\rho_{\mathrm{w}}\right)^{2}(\mathrm{fh})^{4}\left(\mathrm{dT}_{\mathrm{b}} / \mathrm{dZ}\right)}{\left(\mu_{\mathrm{f}}\right)^{2}}\left(\frac{\mu_{\mathrm{f}}}{\mathrm{Cpk}_{\mathrm{f}}}\right)
\end{aligned}
$$

with $\beta=1 / \mathrm{T}_{\mathrm{w}}$.

For the Boussinesq approximation, the terms $\phi_{\mathrm{x}}, \phi_{\mathrm{y}}$, and $\phi_{\mathrm{z}}$ in Eqs. (5), (6) and (7), respectively, are null. Besides, density varies linearly as a function of the temperature only in the buoyancy term of Eq. (6) as:

$$
\rho=\rho_{\mathrm{w}}\left[1-\beta\left(\mathrm{T}-\mathrm{T}_{\mathrm{w}}\right)\right]
$$

\section{SOLUTION METHODOLOGY}

The partial differential equations system was discretized applying the Galerkin finite element technique. An unstructured mesh with triangular elements of six nodes and second-degree interpolation polynomials was used in the numerical solution

\section{R. de Andrade et al. Conjugate Mixed Convection...}

employing the PDEase2D code (Macsyma Inc., 1996). The resultant algebraic equations system was solved by an iterative procedure in a coupled (no-segregated) way combining the Conjugated Gradient (Axelson, 1996) and Newton-Raphson (Ferziger, 1981) methods.

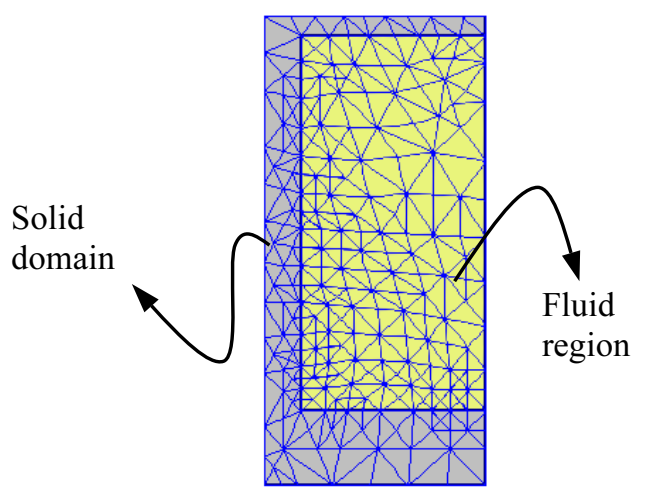

Figure 3. Computational domain with an intermediary mesh in the solution process.

An adaptive scheme was used with successive mesh refinement in the more intense gradient regions. The refinement process can be controlled by a default or a user specified control parameter. As one iteration is completed, an error limit is calculated in each patch of the domain. If this error exceeds the specified value only those patches will be again subdivide. The solid and fluid domains are treated by a coupled way for the conduction Fig. 3 presents an intermediary mesh in the solution process for an aspect ratio $\mathrm{fs} / \mathrm{fh}=0.5$.

\section{SOLUTION}

At the present work, the results using this classical Boussinesq approach were used to validate the numerical solution. Nusselt number (Eq. (12)) and friction factor (Eq. 14) data for the conjugate mixed convection are shown in Fig. 4 at $\mathrm{Re}=1 \cdot 10^{3}, \mathrm{Ra}=4 \cdot 10^{3}$ and $\mathrm{k}_{\mathrm{s}} / \mathrm{k}_{\mathrm{f}}=6 \cdot 10^{3}$ (aluminum/air conductivities representative ratio). The numerical simulations were carried out varying the duct aspect ratio in the range $0.1<\mathrm{fs} / \mathrm{fh}<1.0$. The base-plate, fins and cover plate thickness were maintained constant. Boussinesq results are compared with the parallel-plate reference case (one plate is at a constant temperature and the other is adiabatic) when $\mathrm{Nu}=5.385$ and $\mathrm{fRe}=96$.

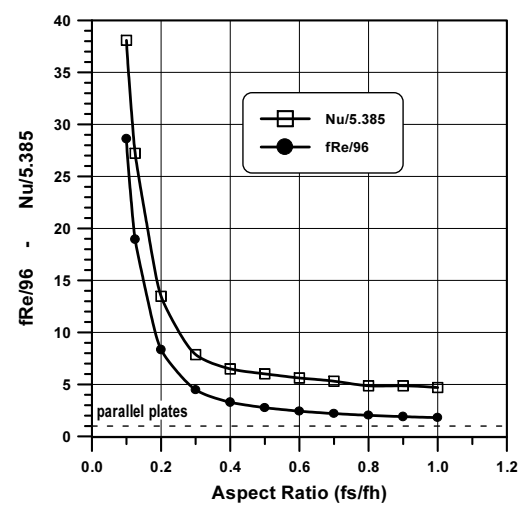

Figure 4. Nusselt number results obtained using the Boussinesq approximation as a function of the duct aspect ratio. 


\section{CIÊNCIA/SCIENCE}

It can be observed that for lower fs/fh ratios the heat transfer rate increases significantly. For $\mathrm{fs} / \mathrm{fh}=1.0$, the fRe product results are near the reference case while the Nusselt number is still higher than the parallel plate value. For lower aspect ratio the mixing secondary flow at the duct transversal section is more intense elevating the heat and momentum transfer when compared with the larger aspect ratios cases. However, for all fs/fh range simulated the air-cooled dissipator is more efficient than the parallel-plate duct due to both heat conduction (in the fin and cover wall) and the secondary flow effect.

For the mixed convection, the gravitational force induces a secondary flow at the duct transversal section that intensifies the heat and momentum transfer. This secondary flow is shown in the velocity vector patterns of the Fig. 5 for $\mathrm{Re}=1 \cdot 10^{3}$, fs/fh $=1.0$ and $\mathrm{k}_{\mathrm{s}} / \mathrm{k}_{\mathrm{f}}=6 \cdot 10^{3}$. At $\mathrm{Ra}=1 \cdot 10^{2}$, the recirculation nuclei is central and it migrates towards the fin region for $\mathrm{Ra}=8 \cdot 10^{3}$, acquiring a boundary layer configuration near the solid wall. Both Boussinesq and non-Boussinesq simulations exhibited this behavior as Rayleigh number increases.
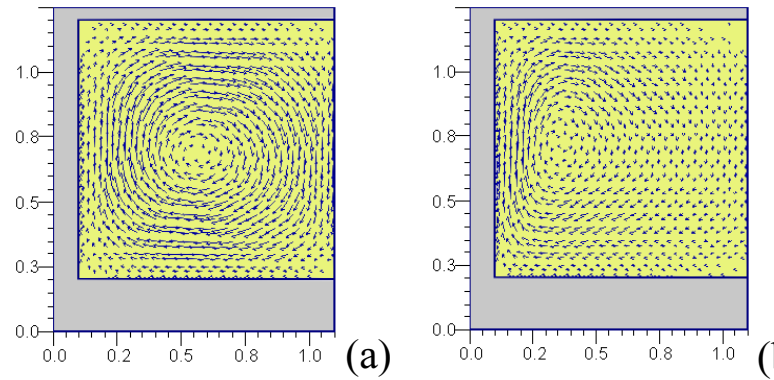

Figure 5. Velocity vector patterns at the duct transversal section: (a) $\mathrm{Ra}=1 \cdot 10^{2}$ and (b) $\mathrm{Ra}=8 \cdot 10^{3}$

The Rayleigh number influence on the fluid meanvelocity profile (determined by Eq. (13)) was also studied, employing the non-Boussinesq approach, as can be seen in Figures 6 and 7 at $\operatorname{Re}=1 \cdot 10^{2}$, fs/fh $=0.5$ and $\mathrm{k}_{\mathrm{s}} / \mathrm{k}_{\mathrm{f}}=6 \cdot 10^{3}$. At $\mathrm{Ra}=2 \cdot 10^{2}$, the forced convection dominates the problem and the $\mathrm{w} / \mathrm{w}_{\mathrm{m}}$ horizontal and vertical distributions present a near-parabolic profile with $\mathrm{w}$-maximum values reaching more than twice the $\mathrm{w}_{\mathrm{m}}$ value. As the Ra number increases, these maximum are smoothed (reaching 1.6 times the $\mathrm{w}_{\mathrm{m}}$ value) and displaced towards the fin region (point 1 in the path 1-2) as shown mainly in Fig. 7 for $\mathrm{Ra}=9 \cdot 10^{4}$.

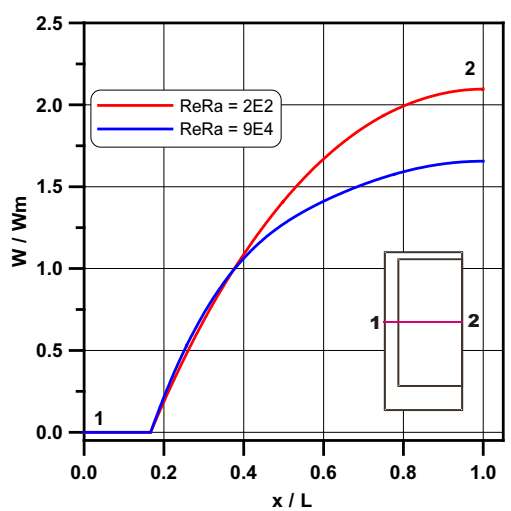

Figure 6. Dimensionless velocity distribution along the duct horizontal middle-plan
C. R. de Andrade et al. Conjugate Mixed Convection...

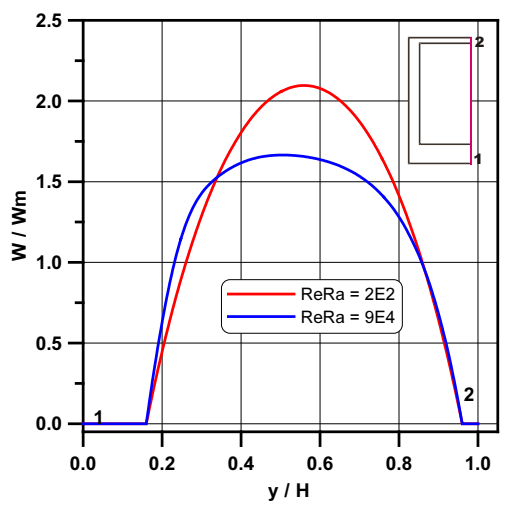

Figure 7. Dimensionless velocity distribution along the duct vertical middle-plan

Temperature profiles along the duct horizontal and vertical middle plans are presented in Figs. 8 and 9 at two different Rayleigh number values, $\mathrm{Re}=1 \cdot 10^{2}, \mathrm{fs} / \mathrm{fh}=$ 0.5 and $\mathrm{k}_{\mathrm{s}} / \mathrm{k}_{\mathrm{f}}=6 \cdot 10^{3}$. At low $\mathrm{Ra}$ number, the natural convection phenomenon isn't pronounced with the maximum temperature values occurring at the duct central region. As Ra number elevates, the secondary circulation induced by the buoyancy effects intensifies the heat transfer process. The horizontal profile (Fig. 8) exhibits a decay in the maximum values but the temperature is more uniform in the duct central region. The vertical middle-plan distribution shows a displacement of the maximum values, with the major temperature gradients concentrated close to the solid wall. A thermal boundary layer formation occurs, similarly to the hydrodynamic boundary layer formation verified in the vector velocity pattern (see Fig. 5b).

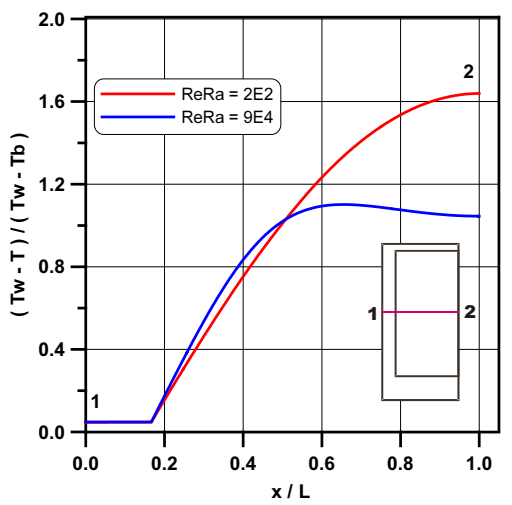

Figure 8. Dimensionless temperature distribution along the duct horizontal middle-plan.

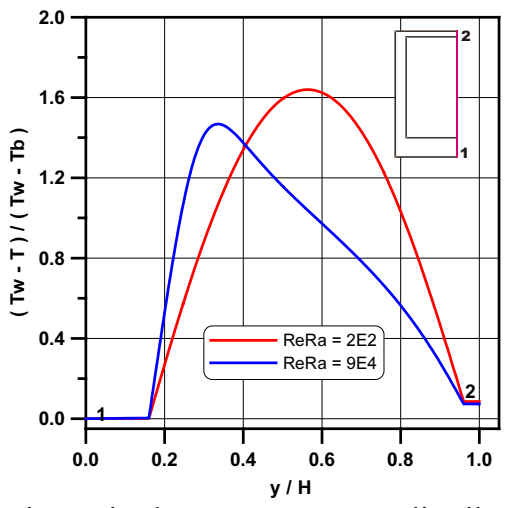

Figure 9. Dimensionless temperature distribution along the duct vertical middle-plan. 


\section{CIÊNCIA/SCIENCE}

The influence of the solid to fluid conductivity ratio in both Nusselt number and friction factor results are presented in Fig. 11 at $\mathrm{Ra}=300, \mathrm{fs} / \mathrm{fh}=0.5$ in the range: $10 \leq \mathrm{k}_{\mathrm{s}} / \mathrm{k}_{\mathrm{f}} \leq 1000$. Fig. 11 shows that the high thermal conductivity of the heat dissipator material is strongly important to enhance the electronic component cooling. The heat transfer rate in the solid domain allows elevating the Nusselt number values as the ratio $k_{s} / k_{f}$ increases. At low $\mathrm{k}_{\mathrm{s}} / \mathrm{k}_{\mathrm{f}}$ values, the solid wall acts as thermal resistances to the heat flux, decreasing the heat removing system performance.

The friction factor isn't significantly affected by the solid wall thermal conductivity variation. The fRe results decays only at lower $\mathrm{k}_{\mathrm{s}} / \mathrm{k}_{\mathrm{f}}$ values. For $\mathrm{k}_{\mathrm{s}} / \mathrm{k}_{\mathrm{f}}>100$, the fRe values are maintained practically constant, although they're almost three times higher than the reference-case (parallel-plate: $f R e=96)$. At $k_{s} / k_{f}=1000$, the heat conduction in the solid domain (fin, base and cover plate) improves the heat transfer rate in until 4.5 times the reference case but this is also accomplished by a friction factor increase.

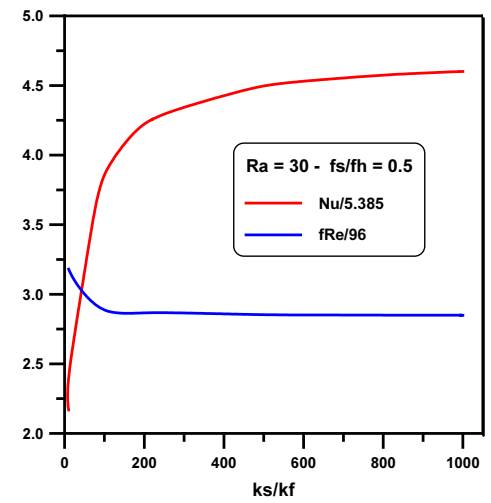

Figure 11. Nusselt number and friction factor results as a function of the solid to fluid conductivity ratio

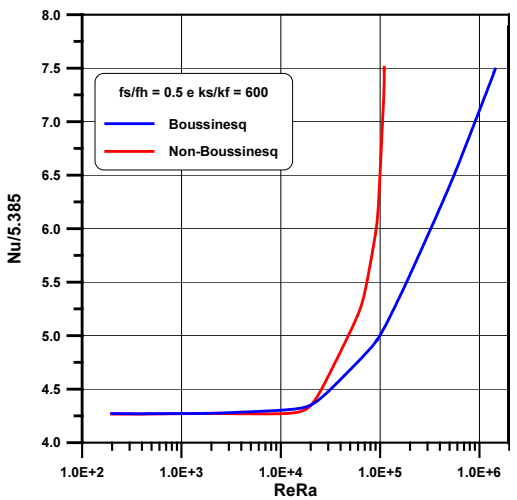

Figure 12. Nusselt number as a function of the ReRa product.

Experimental data correlation of Mori et al. (1966) showed that for the laminar mixed convection in uniformly heated pipes, the Nusselt number could be represented as a function of the Reynolds and Rayleigh numbers (ReRa) product. This fact was confirmed in the DeAndrade and Zaparoli (2000) study for the laminar mixed convection in a horizontal duct using the Boussinesq approach.

At the present work, the non-Boussinesq numerical results also showed dependence from the ReRa product as shown in Tab. $1\left(\mathrm{k}_{\mathrm{s}} / \mathrm{k}_{\mathrm{f}}=600\right.$ and $\left.\mathrm{fs} / \mathrm{fh}=0.5\right)$. For different combinations of Reynolds and Rayleigh

\section{R. de Andrade et al. Conjugate Mixed Convection...}

values, the Nusselt number will be the same if the resultant ReRa don't change.

Table 1. Nusselt number as a function of the Reynolds $\mathrm{x}$ Rayleigh product

\begin{tabular}{c|c|c|c}
\hline Re & Ra & ReRa & Nu \\
\hline 6.4 & 2820 & 18048 & 4.31 \\
64 & 282 & 18048 & 4.31 \\
640 & 28.2 & 18048 & 4.31 \\
\hline
\end{tabular}

Nusselt number data are presented in Fig. 12 by comparison with the Boussinesq approximation results for $\mathrm{k}_{\mathrm{s}} / \mathrm{k}_{\mathrm{f}}=600$ and $\mathrm{fs} / \mathrm{fh}=0.5$. It can be observed that the new considerations (density variations in all terms of the governing equations) elevate the heat transfer rate in comparison with the classical Boussinesq approach in the ReRa range simulated. At $\mathrm{Ra}=1 \cdot 10^{5}$, the Nusselt value is 7.5 times the reference case while this same value is reached only at $\mathrm{Ra}=2 \cdot 10^{6}$ when the Boussinesq approach is employed.

The fact that the density varies inversely with the temperature implies in more intense temperature gradients and consequently in a more accentuated enhancement of both the convection heat transfer coefficient values (Eq. (11)) and the heat transfer rate.

\section{CONCLUSIONS}

At the present work the conjugate laminar mixed convection in a finned heat removing system was numerically studied. The heat transfer rate and the friction factor results obtained under the classical Boussinesq approximation were compared with the nonBoussinesq approach where the density were assumed inversely dependent from the temperature in all terms of the governing equations. These new considerations caused an increase in the Nusselt number values in comparison with the Boussinesq ones when plotted as a function of the ReRa product. The solid to fluid thermal conductivity ratio was also analyzed showing that the heat transfer rate enhances for higher $\mathrm{k}_{\mathrm{s}} / \mathrm{k}_{\mathrm{f}}$ values. 


\section{REFERENCES}

Axelson, O., 1996, "Iterative Solution Methods", Cambridge University Press.

Davis, E. J. and Gill, W. N., 1970, "The Effects of Axial Conduction In The Wall On Heat Transfer With Laminar Flow", Int. J. Heat Mass Transfer, vol. 13, pp 459-470.

DeAndrade, C.R. and Zaparoli, E.L., 2000, "Conjugate Mixed Convection in a Cooling Duct", Proceedings of the Seventh Intersociety Conference on Thermal and Thermomechanical Phenomena in Eletronic Systems, May, 23-26, Nevada, USA.

Ferziger, J. H., 1981, "Numerical Methods for Engineering Application", John Wiley \& Sons.

Fletcher, C. A. J., 1991, Computational Techniques for Fluid Dynamics, Berlin, Springer.

Kraus, A.D, and Bar-Cohen, A., 1995, Design and Analysis of Heat Sinks, John Wiley \& Sons, pp. 407.

Lorenzetti, V., 1989, “Air- and Liquid-Cooled Heat Sinks" in Handbook of Applied Thermal Design, pp. 7.59-7.71, Guyer, E.C. editor, McGraw-Hill, N.Y.

Macsyma Inc, 1996, "PDEase2D - Reference Manual, $3^{\text {rd }}$ edition.

Morcos, S.M. and Bergles, A.E., 1975, "Experimental Investigation of Combined Forced and Free Laminar Convection in Horizontal Tubes", Journal of Heat Transfer, pp. 212-219.

Mori, Y., Futagami, K., Tokuda, S. and Nakamura, M., 1966,"Forced Convective Heat Transfer in Uniformly Heated Horizontal Tubes: Experimental Study on the Effect of Buoyancy", Int. J. Heat Mass Transfer, Vol. 9, pp. 453-463.

Sillekens, J. J. M., Rindt, C. C. M. and Van Steenhoven, A. A., 1998, "Development of Laminar Mixed Convection in a Square Channel with Heated Side Walls", Int. J. Heat and Fluid Flow, vol. 19, pp. 270-281.

Zhong, Z. Y., Yang, K. T. and Lloyd, J. R., 1985, "Variable Property Effects in Laminar Natural Convection in a Square Enclosure", Journal of Heat Transfer, vol. 107, pp. 133-138. 